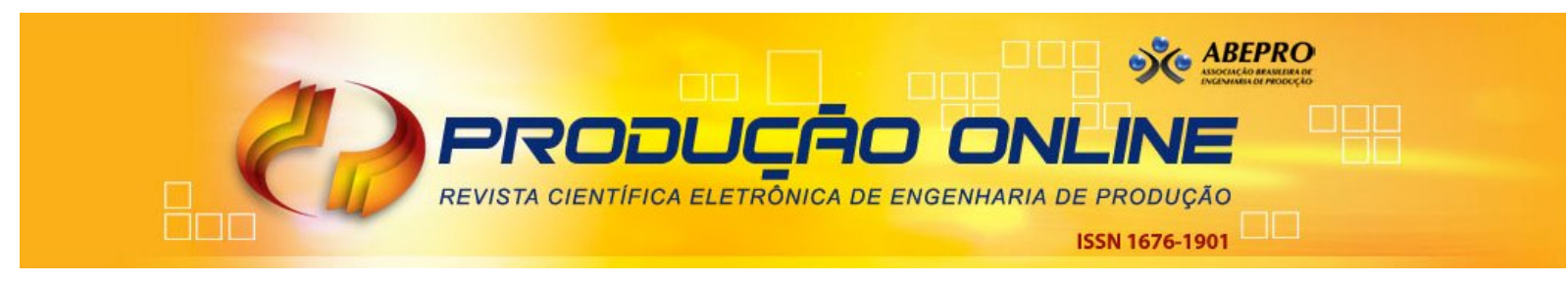

\title{
GESTÃO DE BARREIRAS NA IMPLANTAÇÃO DA PRODUÇÃO ENXUTA: UM ESTUDO NO SETOR AUTOMOBILÍSTICO
}

\section{MANAGEMENT OF BARRIERS TO LEAN PRODUCTION IMPLEMENTATION: A STUDY IN THE AUTOMOTIVE SECTOR}

\author{
Filipe de Almeida Copetti* E-mail: filipe.copetti@ufrgs.br \\ Tarcisio Abreu Saurin* E-mail: saurin@ufrgs.br \\ Marlon Soliman* E-mail: marlon.soliman@ufrgs.br \\ * Universidade Federal do Rio Grande do Sul (UFRGS), Porto Alegre, RS
}

Resumo: Durante o processo de implantação da produção enxuta (PE) é comum surgirem barreiras que dependem do contexto em que ocorre a aplicação. Este estudo tem o objetivo de aperfeiçoar um método de gestão de barreiras à implantação da PE desenvolvido em um estudo anterior. Os aperfeiçoamentos foram desenvolvidos por meio da aplicação do método na área de montagem de para-choques de uma montadora de automóveis. A coleta de dados envolveu 13 entrevistas, observação participante durante 6 meses e análise de documentos relacionados à PE. Dentre os principais aperfeiçoamentos em relação à versão original do método, são destacados o acréscimo de 13 barreiras na lista de barreiras já identificadas na literatura, além da identificação de características contextuais que podem facilitar ou dificultar a aplicação do método.

Palavras-chave: Produção enxuta. Barreiras. Indústria automotiva. Fatores de contexto. Implementação enxuta.

Abstract: During the process of lean production (LP) implementation it is common to arise barriers depending on the context in which the application occurs. This study aims to perfect a method of management the barriers to the implementation of LP developed in a previous study. The improvements were developed by applying the method in the assembly area of bumpers in a car manufacturer. Data collection involved thirteen interviews, participant observation for six months and analysis of LP-related documents. Among the main improvements over the original version of the method, it can be highlighted the addition of thirteen barriers in the list of barriers already identified in the literature, and also the identification of contextual characteristics that can facilitate or hinder the application of the method.

Keywords: Lean Production. Barriers. Automotive industry. Context factors. Lean implementation.

\section{INTRODUÇÃO}

Diversos estudos têm indicado que a implantação dos sistemas de Produção Enxuta (PE) pode impactar positivamente o desempenho organizacional em aspectos como custos, qualidade e tempos de entrega (HOFER et al., 2012; BELEKOUKIAS et al., 2014; CASTILLO et al., 2015). No entanto, devido a sua complexidade, a implantação da PE é difícil e demorada, sendo comuns os casos de 
empresas que não conseguem sustentar os ganhos obtidos nas etapas iniciais de implantação (BHASIN, 2012; TAYLOR et al.; 2013; BORTOLOTTI et al., 2015; SUSILAWATI et al., 2015).

Por exemplo, em uma pesquisa realizada com 2444 respondentes de diversos países pelo Lean Enterprise Institute (2007), concluiu que apenas 7\% das empresas estavam em um estágio avançado de PE, sendo que 48\% estavam em estágio inicial e 11\% estavam planejando adotar a PE. Bhasin e Burcher (2006) examinam as razões das baixas taxas de implantações avançadas da PE, concluindo que é necessário mudar a cultura da organização, não bastando aplicar somente as práticas operacionais da PE.

Deste modo, estudos têm sido realizados acerca das dificuldades de implantação da PE. Scherer e Ribeiro (2013) usam princípios do gerenciamento de riscos para estimar a probabilidade de sucesso da implantação da PE a partir da identificação de fatores de risco. Outros autores (SIM; ROGERS, 2009; SOUZA; PIDD, 2011; AlJ et al., 2013; JADHAV et al., 2014; SHANG; PHENG, 2014; Marodin e Saurin, 2015), usam o termo barreiras para designar as dificuldades de implantação da PE, enfatizando, dessa forma, a análise da situação atual ao invés da antecipação de um processo futuro. Por exemplo, Aij et al. (2013) identificaram barreiras para a implementação da PE em um hospital, tal como a falta de integração entre a PE e o planejamento estratégico do hospital. Marodin e Saurin (2015) criaram um método que visa auxiliar as empresas no gerenciamento das barreiras da implantação da PE, visando o entendimento da natureza das barreiras, suas origens, priorização, inter-relações e relações com o contexto organizacional. Tal método foi testado por aqueles autores em uma empresa de manufatura nos EUA.

O presente trabalho tem como objetivo principal o aperfeiçoamento do método proposto por Marodin e Saurin (2015), aplicando-o em um contexto brasileiro e contribuindo para o preenchimento de lacunas e oportunidades futuras identificadas na aplicação original do método. Dentre essas, podem ser salientadas: (i) a necessidade de testar a ferramenta em diferentes contextos, setores, países e níveis de maturidade da PE; (ii) o desenvolvimento de mecanismos para monitorar 
as mudanças no contexto, uma vez que elas podem disparar mudanças nas barreiras; e (iii) a construção de meios para o gerenciamento das barreiras.

Este método foi escolhido como foco deste estudo porque, diferentemente de trabalhos anteriores, ele contempla a identificação, análise das relações, priorização e controle das barreiras para a implantação da PE, levando em conta o contexto. Até então, nenhum outro estudo havia abordado essas questões de forma simultânea, nem estabelecido a conexão entre barreiras e fatores de contexto (MARODIN; SAURIN, 2015).

A replicação do método em um novo contexto contribui para avaliar a capacidade de generalização das suas etapas e identificar dificuldades não percebidas na concepção original da ferramenta. Com isso, a nova aplicação realizada neste estudo aprofunda o conhecimento de como os fatores de contexto influenciam as barreiras, bem como atualiza e expande a lista de barreiras já identificadas em estudos anteriores.

\section{REFERENCIAL TEÓRICO}

\subsection{Fatores de contexto que influenciam a aplicação da PE}

Neste estudo, contexto é definido como o conjunto de fatores subjacentes às barreiras para a implantação da PE que influenciam as mesmas. Os fatores de contexto são parciais, no sentido de que o seu impacto pode ser positivo para algumas barreiras e negativo para outras, dependendo da sua relação individual com cada barreira. Uma revisão da literatura realizada por Marodin e Saurin (2013) identificou 25 fatores de contexto que afetam a implantação da PE, conforme mostrado no Quadro 1. 
Quadro 1 - Fatores de contexto que afetam a Implantação da PE

\begin{tabular}{|c|c|}
\hline Áreas & Fatores \\
\hline \multirow{2}{*}{ 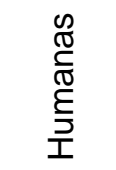 } & Habilidade, experiência e conhecimento para conduzir o processo de implantação da PE \\
\hline & Força de trabalho jovem \\
\hline \multirow{16}{*}{ 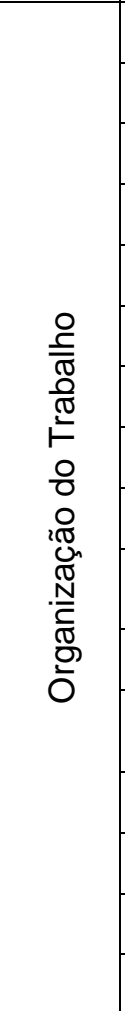 } & Objetivos a médio e longo prazo \\
\hline & Cultura organizacional receptiva a mudanças \\
\hline & Confiança na importância da PE para a empresa \\
\hline & Autonomia dos operadores \\
\hline & Apoio e comprometimento da gerência \\
\hline & Apoio e comprometimento da força de trabalho \\
\hline & Segurança no emprego entre os funcionários \\
\hline & Estratégia e indicadores consistentes com a PE \\
\hline & Estratégia de mudança sistemática e controlada \\
\hline & Uso de métricas de desempenho operacional, ao invés de medidas contábeis tradicionais \\
\hline & Existência de comunicação sobre o processo de implantação da PE \\
\hline & $\begin{array}{l}\text { A transição de produção em massa para LP é mais fácil do que a transição da produção } \\
\text { artesanal para LP }\end{array}$ \\
\hline & Integração entre departamentos \\
\hline & Métodos para sustentar a implantação em longo prazo \\
\hline & Sistema de recompensa e bônus consistente com a PE \\
\hline & Empregados envolvidos com melhorias \\
\hline \multirow{5}{*}{ 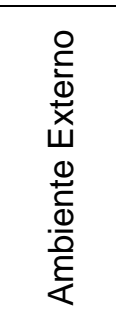 } & $\begin{array}{l}\text { Tamanho da empresa: as grandes empresas são geralmente mais bem sucedidas em } \\
\text { implementação }\end{array}$ \\
\hline & Disponibilidade de recursos financeiros e humanos \\
\hline & Posição dominante da empresa em relação aos seus clientes \\
\hline & O sindicalismo, a cultura nacional e a história da planta em PE \\
\hline & Força do relacionamento com os fornecedores \\
\hline \multirow{2}{*}{$\begin{array}{l}0 \\
0 \\
.0 \\
\bar{D} \\
\stackrel{\mathbb{U}}{1}\end{array}$} & Baixa variedade de produtos \\
\hline & $\begin{array}{l}\text { Tipo de sistema de produção (por exemplo, é mais fácil de implementar PE em linhas e } \\
\text { células, em relação ao job-shops) }\end{array}$ \\
\hline
\end{tabular}

Fonte: Adaptado de Marodin e Saurin (2013)

Os 25 fatores identificados no Quadro 1 foram divididos em 4 categorias que formam o sistema sócio-técnico. A dimensão humana refere-se à composição da mão-de-obra e ao domínio das habilidades técnicas e pessoais para suportar a implantação enxuta. A segunda categoria, que compreende mais da metade dos fatores levantados, destina-se a avaliar como as práticas e costumes de organização do trabalho moldam o ambiente interno. A terceira categoria, por sua vez, identifica

Revista Produção Online, Florianópolis, SC, v. 16, n. 1, p. 313-341, jan./mar. 2016. 
como os fatores externos podem contribuir ou impor obstáculos na jornada enxuta, enquanto a última categoria analisa a influência dos fatores técnicos, tais como a variedade de produtos e o tipo de sistema de produção.

\subsection{Barreiras para implantação da PE}

Durante o processo de implantação da PE surgem barreiras que podem ser definidas como qualquer problema técnico, organizacional ou social que comprometa a eficiência e a eficácia do processo de implantação (MARODIN; SAURIN, 2015). Na literatura encontram-se diferentes termos para barreiras, tais como fatores de risco (SCHERER; RIBEIRO, 2013) e dificuldades para da implantação (VINODH et al., 2011). Pode-se também considerar como barreiras o oposto dos fatores de sucesso, como os identificados por Dennis (2008) e Boyle et al. (2012).

O Quadro 2 esquematiza uma lista de barreiras que foram identificadas a partir de uma revisão da literatura. Ao todo foram 20 barreiras identificadas, sendo 14 referenciadas em Marodin e Saurin (2015) e seis delas com base em outros autores.

Quadro 2 - Lista das Barreiras para a Implantação da PE

(Continua)

\section{Barreiras para a Implantação da PE}

1 - Dificuldade de adaptar as práticas e princípios da PE ao contexto da empresa. (Emiliani \& Stec, 2005)

2 - Falta de conhecimento das áreas de apoio (Compras, Engenharia e Manutenção) para orientar o andamento da implantação da PE no chão de fábrica. (Marodin e Saurin, 2015)

3 - A aplicação de práticas da PE no chão de fábrica de forma pontual, sem consideração das relações entre as práticas dessas com outras rotinas gerenciais da empresa. (Achanga et al., 2006)

4 - Falta de recursos humanos destinados a planejar e a implantar melhorias. (Marodin e Saurin, 2015)

5 - Falta de recursos financeiros destinados a planejar e a implantar melhorias. (Marodin e Saurin, 2015)

6 - Falta de clareza na comunicação para todos os funcionários sobre o início e o progresso da implantação. (Marodin e Saurin, 2015)

7 - Priorizar ações de impacto em indicadores de curto prazo, sem valorizar melhorias qualitativas ou de maior resultado a médio e longo prazo. (Marodin e Saurin, 2015)

8 - O sistema de medição de desempenho e reconhecimento de pessoas e processos não é compatível com as práticas e princípios da PE. (Marodin e Saurin, 2015)

9 - Não sustentar as melhorias a médio e longo prazo. (Marodin e Saurin, 2015) 
Quadro 2 - Lista das Barreiras para a Implantação da PE

(Conclusão)

\section{Barreiras para a Implantação da PE}

10 - Dificuldades na gestão do processo de implantação das melhorias. (Marodin e Saurin, 2015)

11 - Dificuldade de envolver os demais setores da empresa (Vendas, Marketing e logísticas, por exemplo) na implantação da PE no chão de fábrica. (Bhasin, 2012)

12 - A melhoria contínua dos processos através do uso das práticas e princípios da PE não é considerada como prioritária, estratégica e essencial para a empresa. (Moyano-Fuentes \& SacristánDíaz, 2012)

13 - Falta de apoio e participação ativa da média e alta gerência na implantação de melhorias. (Marodin e Saurin, 2015)

14 - Falta de uma visão clara e direcionada da alta gerência sobre o caminho da implantação da PE. (Marodin e Saurin, 2015)

15 - Os gerentes e diretores não terem o conhecimento suficiente sobre a PE. (Marodin e Saurin, 2015)

16 - Os funcionários da empresa não estão acostumados com mudanças e melhorias nos processos. (Saurin et al., 2010)

17 - O nível operacional não apoia a implantação da PE. (Marodin e Saurin, 2015)

18 - Falta de treinamento, envolvimento e autonomia para os operadores realizarem as novas atribuições decorrentes da implantação da PE. (Marodin e Saurin, 2015)

19 - Os operadores temem serem demitidos em função do excesso de mão de obra gerado pelas melhorias implantadas. (Marodin e Saurin, 2015)

20 - Existem outras filosofias e estratégias de melhoria que competem com a PE, havendo pontos de conflito entre as mesmas. (Emiliani e Stec, 2005)

A lista de barreiras contida no Quadro 2 foi utilizada como base para a identificação de barreiras na empresa estudada. Além disso, pode-se a partir dela identificar novas barreiras, contribuindo-se assim com o estado da arte do tema em questão.

\section{MÉTODO DE PESQUISA}

Inicialmente, foi necessário selecionar uma empresa para se realizar a aplicação prática do estudo de caso. Para tanto, escolheu-se uma multinacional do setor automotivo, devido a sua grande importância regional e a complexidade do processo produtivo. O setor estudado da planta é responsável pela pintura e montagem de polímeros que serão aplicados aos veículos fabricados. A escolha desse setor justifica-se pelas dificuldades verificadas em atender as metas estipuladas em termos de qualidade e capacidade de resposta.

O método utilizado no trabalho divide-se em cinco etapas (Quadro 3), sendo adaptado de Marodin e Saurin (2015). A primeira etapa compreendeu a descrição do contexto do caso estudado. Para isso, buscou-se primeiramente entender o 
processo produtivo da empresa, através da elaboração de um mapa do processo. Em conjunto, caracterizou-se o ambiente externo, operacional, social e a organização do trabalho, bem como analisou-se o histórico do processo de implantação da PE na empresa.

Quadro 3 - Etapas do método

\begin{tabular}{|c|c|}
\hline Etapas do método & Fontes de dados \\
\hline E1-Descrição do contexto & $\begin{array}{l}\text { Observação participante; análise de documentos da empresa relacionados a PE; e entrevistas } \\
\text { com dois membros experientes do setor, através dos formulários A e B sugeridos por Marodin } \\
\text { et al. (2014). }\end{array}$ \\
\hline $\begin{array}{l}\text { E2-Identificação das } \\
\text { barreiras; }\end{array}$ & $\begin{array}{l}\text { Reunião com o time de melhoria contínua do setor; } 13 \text { entrevistas individuais; e lista de } \\
\text { barreiras. }\end{array}$ \\
\hline $\begin{array}{l}\text { E3-Influência dos fatores de } \\
\text { contexto nas barreiras. }\end{array}$ & $\begin{array}{l}\text { Observação participante; conversas com membros do time de melhoria contínua; resultados } \\
\text { da descrição do contexto (E1); e lista de barreiras priorizadas. }\end{array}$ \\
\hline $\begin{array}{l}\text { E4-Análise da relação entre } \\
\text { barreiras e sua priorização }\end{array}$ & $\begin{array}{l}\text { Lista de barreiras; observação participante; conversas com membros do time de melhoria } \\
\text { contínua. }\end{array}$ \\
\hline $\begin{array}{l}\text { E5-Plano de ação para } \\
\text { controlar as barreiras e sua } \\
\text { análise }\end{array}$ & Reunião com os responsáveis pelo setor; resultados das etapas anteriores. \\
\hline
\end{tabular}

A segunda etapa do método constituiu-se da identificação das barreiras da implantação da PE. Inicialmente, foi realizada uma reunião com cinco membros do time de melhoria contínua, para mostrar as barreiras já identificadas na literatura e identificar outras presentes no setor. Através dessa conversa e da observação participante dos autores, descobriu-se sete novas barreiras. Após, realizou-se treze entrevistas individuais com membros envolvidos na implantação da PE e membros da produção. Cada entrevista possuiu duração média de quarenta e cinco minutos e foi dividida em três partes. Primeiramente, questionou-se como o entrevistado estava envolvido com a PE. Em seguida, verificaram-se quais eram as principais barreiras identificadas pelo entrevistado na implantação da PE. Por último, foi apresentada ao entrevistado uma lista com as vinte barreiras identificadas na literatura, acrescida com as sete barreiras identificadas na reunião inicial. O entrevistado teve de avaliar a intensidade dessas vinte e sete barreiras, fornecendo notas de 1 (intensidade muito baixa) até 5 (intensidade muito alta). Ao término, calculou-se a média das intensidades de cada barreira. Em função do grande 
número de barreiras identificadas, foi acrescentada uma etapa de priorização, reduzindo-se o número de barreiras analisadas no restante do método.

A terceira etapa do método consistiu na análise da influência dos fatores de contexto nas barreiras da implantação da PE identificadas e priorizadas. Para tanto, elaborou-se um quadro com os fatores de contexto nas linhas e as barreiras nas colunas. No espaço de encontro entre as linhas e as colunas, preencheu-se com um sinal de positivo (o fator de contexto amplifica o efeito da barreira) ou negativo (se o fator de contexto diminui o efeito da barreira).

$\mathrm{Na}$ quarta etapa, analisou-se a relação entre as barreiras para a implantação da PE através do método ISM (SAGE, 1977). Elaborou-se uma matriz com as barreiras listadas nas linhas e nas colunas, preenchendo-se os cruzamentos com o valor "1" caso as barreiras influenciam-se mutuamente, e "0" caso contrário. A matriz foi preenchida pelos autores baseado nas barreiras identificadas e no contexto da empresa. A partir da análise, as barreiras foram classificadas em quatro tipos: autônomas (baixa dependência e baixo poder de influência); independentes (baixa dependência e alto poder de influência); dependentes (alta dependência e baixo poder de influência); e de união (alta dependência e alto poder de influência). As barreiras foram ainda classificadas em níveis hierárquicos, verificando-se, para cada barreira, as demais que são influenciadas por esta, e como esta é dependente das demais. Uma representação gráfica foi elaborada para demonstrar essa relação, possibilitando identificar quais barreiras serão reduzidas ao se intervir em outra.

A quinta etapa do método consistiu numa reunião com duração de cerca de duas horas com os responsáveis do setor analisado para apresentação do estudo e para a elaboração de um plano de ação. Adicionou-se ao método de Marodin e Saurin (2015) uma avaliação do plano de ação elaborado, através da análise do potencial de abrangência de cada ação dentro do contexto da empresa. Para isso, construiu-se um quadro com as ações nas linhas e os fatores de contexto nas colunas. No espaço de encontro entre as linhas e as colunas, colocou-se um sinal de positivo (a ação amplifica o efeito do fator) ou negativo (a ação atenua o efeito do fator). A análise deste quadro permite visualizar o potencial de cada ação na diminuição das barreiras através do contexto e também analisar quais fatores de contexto estão sendo abrangidos pelo plano de ação. 
Posteriormente a aplicação do método, realizou-se uma análise comparativa dos resultados encontrados neste estudo com aqueles reportados por Marodin e Saurin (2015). Os resultados dos dois estudos foram comparados sob a luz de seis critérios: número de entrevistados; número de barreiras; média de intensidade das barreiras; número de barreiras priorizadas; número de fatores de contexto analisados; e número de ações elaboradas no estudo. Dessa forma, pode-se obter uma análise completa das diferenças e semelhanças entre os estudos, além de compreender como o método se adaptou à nova aplicação.

\section{RESULTADOS}

\subsection{Descrição do Contexto}

O cenário estudado é o setor de pintura e montagem de para-choques (Setor A) de uma empresa multinacional do ramo automobilístico, situada no Brasil há 88 anos. A empresa já possui um sistema de manufatura baseado na PE que é comum a todas as suas plantas. Devido à planta estudada ser recente (15 anos), o seu layout foi planejado para um processo de PE. Dessa forma, a implantação da PE na planta está num nível superior à maioria das empresas situadas no Brasil. $\mathrm{O}$ processo produtivo do setor divide-se em duas etapas: a pintura do polímero e a montagem de acessórios ao polímero pintado, conforme mostrado na Figura 1.

A pintura inicia-se com o carregamento de polímeros, passando por máquinas de lavagem (desengraxe e água) e secagem automatizadas. Após, o polímero entra na cabine de pintura, onde é aplicado manualmente o promotor, base e verniz, seguindo para a secagem em estufa. Na etapa final da pintura, ocorre a verificação manual de cada peça produzida para garantir a qualidade do produto, e a retirada da peça da linha de produção para o estoque.

Já a segunda parte do processo é a montagem final da peça (para-choque) em quatro células produtivas, que se inicia com o sequenciamento das peças requeridas pela área de programação da produção. As peças com seus componentes são carregadas em máquinas que realizam a montagem final, seguem para a inspeção visual da equipe de qualidade, e são então enviadas para o cliente interno.

Revista Produção Online, Florianópolis, SC, v. 16, n. 1, p. 313-341, jan./mar. 2016. 
Figura 1 - Mapa do processo do setor estudado

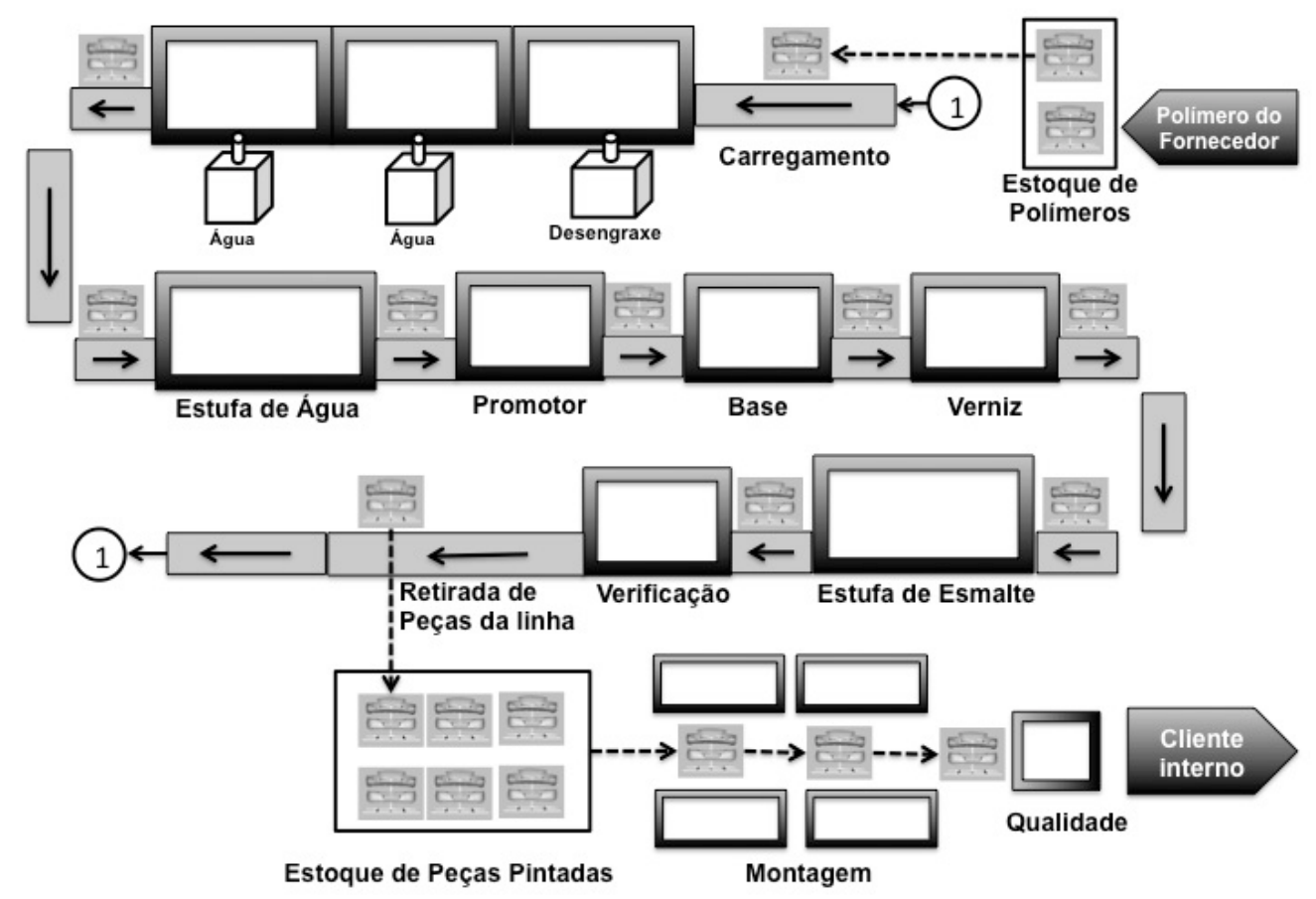

A partir de entrevistas com os responsáveis pelo setor e documentos coletados, elaborou-se o Quadro 4, que resume as características dos quatro subsistemas (ambiente externo, operacional, social e organização do trabalho) formando o sistema sócio técnico.

Quadro 4 - Sistema Sócio-técnico do setor estudado (Continua)

\begin{tabular}{|l|}
\hline \multicolumn{1}{|c|}{ Subsistema Ambiente Externo } \\
\hline A planta está localizada na região sul, afastada do principal centro industrial do país. \\
\hline A planta possui 15 anos e o setor estudado possui 9 anos. \\
\hline O fornecedor principal do setor está localizado ao lado da planta. \\
\hline O cliente interno do setor está localizado a 500 metros do setor. \\
\hline O setor é considerado pela planta como um fornecedor interno. \\
\hline \multicolumn{1}{c|}{ Subsistema Técnico } \\
\hline $\begin{array}{l}\text { O setor produz nove modelos de para-choques pintados com } 5 \text { cores diferentes e três acessórios } \\
\text { esportivos com } 2 \text { cores diferentes. }\end{array}$ \\
\hline Cada produto tem em média 4 a 10 componentes. \\
\hline $\begin{array}{l}\text { O setor pode ser dividido em duas partes: pintura (layout em linha fechada); e montagem (layout em } \\
\text { células). }\end{array}$ \\
\hline O setor possui estoque de dois dias para a pintura; a montagem não possui estoque. \\
\hline \multicolumn{1}{c|}{ Subsistema Social } \\
\hline
\end{tabular}


Quadro 4-Sistema Sócio-técnico do setor estudado

(Conclusão)

Cerca de 40 operadores por turno.

A pintura, por ser manual, requer maior nível de treinamento prático. Isso dificulta a flexibilidade.

\section{Subsistema Organização do trabalho}

O gerente do setor responde pelos resultados diretamente para o diretor de produção da planta;

Subordinados diretamente ao gerente existem 4 supervisores.

Cada turno tem um líder de produção que é subordinado ao supervisor de produção do turno. O líder administra 5 facilitadores e 40 operadores de produção.

Um supervisor é responsável, exclusivamente, por melhoria contínua e manutenção, administrando um técnico de manufatura e um especialista, assim como 3 líderes de manutenção.

O gerente e os supervisores do setor são também responsáveis por outro setor da planta, sendo seu escritório localizado nesse setor.

Os indicadores de cada time do setor estão dispostos em quadros nas áreas de cada time e se referem à segurança, pessoas, qualidade, capacidade de resposta, custos e meio ambiente.

Existe um programa de sugestões implantado na planta.

\subsection{Identificação das barreiras}

A Tabela 1 apresenta a intensidade média, de acordo com a percepção dos treze entrevistados, de cada uma das 27 barreiras identificadas no setor.

As barreiras B21, B22, B23, B24, B25, B26 e B27 foram identificadas pelos autores em conjunto com membros do time de melhoria contínua do setor. Através das médias das entrevistas, verifica-se que três dessas barreiras (B22, B27 e B23) estão entre as barreiras com intensidade superior a 3 pontos e nenhuma das outras quatro barreiras têm intensidade percebida inferior a 2,5 pontos. Isso demonstra a importância dessas sete barreiras para o desenvolvimento da implantação da PE no setor e, também, a necessidade de incrementar a lista de barreiras identificadas na literatura.

Para as etapas posteriores do método, foram consideradas as barreiras com intensidade média igual ou maior de 3 pontos, em virtude do expressivo número de barreiras identificadas nessa etapa. Dessa forma, prioriza-se as barreiras com maior intensidade, qualificando-se a análise de suas causas e a criação de um plano de ação para a sua atenuação. 
Tabela 1 - Intensidade das barreiras para a Implantação da PE no setor

Barreiras para a Implantação da PE

B5 - Falta de recursos financeiros destinados a planejar e a implantar melhorias

B22 - Dificuldade em encontrar fornecedores que utilizam a PE, entregando peças com qualidade e pontualidade

B27 - Dificuldade de criar uma cultura de controle e transparência de indicadores operacionais para atacar o desperdício

B10 - Dificuldades na gestão do processo de implantação das melhorias

B19 - Os operadores temem serem demitidos em função do excesso de mão de obra gerado pelas melhorias implantadas

B23 - Falta de compreensão da importância de utilizar as práticas enxutas diariamente

B4 - Falta de recursos humanos destinados a planejar e a implantar melhorias

B7 - Priorizar ações de impacto em indicadores de curto prazo, sem valorizar melhorias qualitativas ou de maior resultado a médio e longo prazo

B9 - Não sustentar as melhorias a médio e longo prazo

B17 - O nível operacional não apoia a implantação da Produção Enxuta (Melhoria Contínua)

B1 - Dificuldade de adaptar as práticas e princípios da Produção Enxuta ao contexto do setor de Pintura de Para-choques

B6 - Falta de clareza na comunicação para todos os funcionários sobre o início e o progresso da implantação da Produção Enxuta

B26 - Necessidade de alteração da cultura da empresa, não apenas a utilização de práticas da PE

B18 - Falta de envolvimento e autonomia para os operadores realizarem as novas atribuições decorrentes da implantação da Produção Enxuta, por exemplo, dar sugestões e acionar o Andon

B2 - Falta de conhecimento das áreas de apoio (PCP, Qualidade, Engenharia e Manutenção) para orientar o andamento da implantação da Produção Enxuta (Melhoria Contínua) no chão de fábrica

B3 - A aplicação de práticas da Produção Enxuta no chão de fábrica de forma pontual, sem consideração das relações entre as práticas e dessas com outras rotinas gerenciais da empresa

B11 - Dificuldade de envolver os demais setores da empresa (ex. vendas, marketing, logísticas,

desenvolvimento de produtos, financeiro) na implantação da Produção Enxuta no chão de fábrica

B21 - Falta de habilidade dos gestores para liderar a implantação da Produção Enxuta (Melhoria Contínua)

B24 - Não visualizar a PE como um sistema de produção, aplicando apenas algumas de suas práticas

B16 - Os funcionários da empresa não estão acostumados com mudanças e melhorias nos processos

B25 - Dificuldade da gerência em repassar a importância do foco no cliente (não repassar defeitos) para o nível operacional

B13 - Falta de apoio e participação ativa da média e alta gerência na implantação de melhorias

B14 - Falta de uma visão clara e direcionada da alta gerência sobre o caminho da implantação da Produção Enxuta (Melhoria Contínua)

B8 - O sistema de medição de desempenho de pessoas e processos não é compatível com as práticas e princípios da Produção Enxuta

B20 - Existem outras filosofias e estratégias de melhoria que competem com a Produção Enxuta, havendo pontos de conflito entre as mesmas

B12 - A melhoria contínua dos processos através do uso das práticas e princípios da Produção Enxuta não é considerada como prioritária para a empresa

B15 - Os gerentes e diretores não terem o conhecimento suficiente sobre Produção Enxuta
Média da Intensidade

Revista Produção Online, Florianópolis, SC, v. 16, n. 1, p. 313-341, jan./mar. 2016. 


\subsection{Influência dos fatores de contexto nas barreiras}

Os fatores de contexto do setor foram identificados a partir da análise do contexto sócio-técnico (Quadro 4) e do histórico de PE do setor. Dessa forma foram encontrados 28 fatores que foram classificados em externo (8 fatores), organização do trabalho (10 fatores), social (4 fatores) e técnico (6 fatores). Com a elaboração dos fatores analisou-se a influência de cada fator em relação às barreiras, conforme mostrado no Quadro 5.

Quadro 5 - Influência dos fatores de contexto nas barreiras

\begin{tabular}{|c|c|c|c|c|c|c|c|c|c|c|c|c|c|}
\hline N. & Classificação & $\begin{array}{l}\text { Influência dos } \\
\text { Fatores nas } \\
\text { Barreiras } \\
\end{array}$ & B5 & B22 & B27 & B10 & B19 & B23 & B4 & B7 & B9 & B17 & B1 \\
\hline F1 & Externo & $\begin{array}{l}\text { A planta está } \\
\text { localizada na região } \\
\text { sul, afastada do } \\
\text { principal centro } \\
\text { industrial do País. }\end{array}$ & & + & & & & & & & & & \\
\hline F2 & Externo & $\begin{array}{ll}\text { O setor possui } & 9 \\
\text { anos, enquanto a } & \text { a } \\
\text { planta possui } 15 .\end{array}$ & & & & & & & + & + & & & \\
\hline F3 & Externo & $\begin{array}{l}\text { O setor está } \\
\text { localizado ao lado } \\
\text { do seu cliente } \\
\text { interno. }\end{array}$ & & & - & & & & & + & & & \\
\hline F4 & Externo & $\begin{array}{l}\text { Proximidade } \text { com } \\
\text { apenas um dos } \\
\text { seus principais } \\
\text { fornecedores. }\end{array}$ & & & & & & & & & & & + \\
\hline F5 & Externo & $\begin{array}{l}\text { Assistência técnica } \\
\text { fixa no setor por } \\
\text { parte do seu } \\
\text { fornecedor químico. }\end{array}$ & & - & & & & & - & & - & & - \\
\hline F6 & Externo & $\begin{array}{l}\text { Auditoria constante } \\
\text { sobre o seguimento } \\
\text { do sistema global } \\
\text { de manufatura da } \\
\text { empresa. }\end{array}$ & & & - & & & - & & & & & \\
\hline F7 & Externo & $\begin{array}{l}\text { O setor é } \\
\text { considerado um } \\
\text { fornecedor interno } \\
\text { do produto principal } \\
\text { da empresa. }\end{array}$ & + & & & + & & & + & & & & \\
\hline F8 & Externo & $\begin{array}{l}\text { A criação de novos } \\
\text { produtos não é } \\
\text { realizada na planta. }\end{array}$ & & & & + & & & & & & & \\
\hline F9 & Organizacional & $\begin{array}{l}\text { O setor foi anexado } \\
\text { recentemente a um } \\
\text { novo setor, antes } \\
\text { era pertencente a } \\
\text { outro setor da } \\
\text { planta. }\end{array}$ & + & & + & + & & & + & & & & + \\
\hline
\end{tabular}


Quadro 5 - Influência dos fatores de contexto nas barreiras

(Continuação)

\begin{tabular}{|c|c|c|c|c|c|c|c|c|c|c|c|c|c|}
\hline F10 & Organizacional & $\begin{array}{l}\text { Três turnos de } \\
\text { trabalho. }\end{array}$ & & & + & + & & + & & & + & + & \\
\hline F11 & Organizacional & $\begin{array}{l}\text { Compartilhamento } \\
\text { do gerente e do } \\
\text { supervisor com } \\
\text { outro setor, assim } \\
\text { como indicadores } \\
\text { reportados para a } \\
\text { planta. }\end{array}$ & + & & + & + & & & + & + & + & & \\
\hline F12 & Organizacional & $\begin{array}{l}\text { Distância física do } \\
\text { setor com a sala do } \\
\text { gerente e dos } \\
\text { supervisores. }\end{array}$ & & & + & + & & & & + & + & + & \\
\hline F13 & Organizacional & $\begin{array}{l}\text { Possui } \\
\text { especialista } \\
\text { dedicado } \\
\text { melhoria contínua } \\
\text { do setor. }\end{array}$ & & - & - & - & & - & & & - & & - \\
\hline F14 & Organizacional & $\begin{array}{lr}\text { O setor segue } & \text { o } \\
\text { sistema global } & \text { de } \\
\text { manufatura } & \text { da } \\
\text { empresa que } & \text { é } \\
\text { baseado na PE. } & \\
\end{array}$ & & & - & & - & - & & - & & & - \\
\hline F15 & Organizacional & $\begin{array}{l}\text { A equipe de } \\
\text { melhoria contínua } \\
\text { foi recentemente } \\
\text { formada, não } \\
\text { possuindo } \\
\text { representante em } \\
\text { todos os turnos. }\end{array}$ & & & + & + & & + & & + & + & & \\
\hline F16 & Organizacional & $\begin{array}{l}\text { Dificuldade } \quad \text { em } \\
\text { treinar operadores } \\
\text { pintores, menor } \\
\text { flexibilidade. }\end{array}$ & & & & & & & + & & & & \\
\hline F17 & Organizacional & $\begin{array}{l}\text { Existe um } \\
\text { treinamento mensal } \\
\text { com todos os } \\
\text { operadores. }\end{array}$ & & & - & & - & - & & & & - & - \\
\hline F18 & Organizacional & $\begin{array}{lr}\text { Os facilitadores } \\
\text { estão } & \\
\text { frequentemente } \\
\text { trabalhando na } \\
\text { linhar nom } \\
\text { operadores. }\end{array}$ & & & + & & & + & & & & + & \\
\hline F19 & Social & 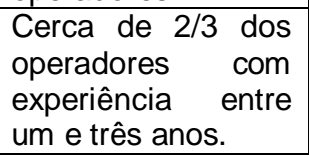 & & & & & + & + & & & & + & \\
\hline $\mathrm{F} 20$ & Social & $\begin{array}{l}\text { Praticamente todos } \\
\text { os colaboradores } \\
\text { do setor realizaram } \\
\text { os treinamentos } \\
\text { básicos sobre PE. }\end{array}$ & & & & & & - & & & & - & \\
\hline F21 & Social & $\begin{array}{l}\text { Grande tempo de } \\
\text { empresa por parte } \\
\text { do time de melhoria } \\
\text { contínua. }\end{array}$ & & & & - & & - & & - & - & & - \\
\hline
\end{tabular}

Revista Produção Online, Florianópolis, SC, v. 16, n. 1, p. 313-341, jan./mar. 2016. 


\begin{tabular}{|c|c|c|c|c|c|c|c|c|c|}
\hline F22 & Social & $\begin{array}{lr}\text { Facilitadores } & \text { com } \\
\text { pouco tempo } & \text { de } \\
\text { experiência } & \text { na } \\
\text { função. } & \\
\end{array}$ & & + & + & + & & & \\
\hline F23 & Técnico & $\begin{array}{l}\text { A empresa não } \\
\text { possui benchmarks } \\
\text { interno no processo } \\
\text { do setor, devido à } \\
\text { terceirização desse } \\
\text { setor na maioria de } \\
\text { suas plantas. }\end{array}$ & & & + & & & & + \\
\hline F24 & Técnico & $\begin{array}{lr}\text { A pintura do } & \text { do } \\
\text { polímero } & \text { é } \\
\text { realizada } & \\
\text { manualmente. } & \end{array}$ & & & & & + & + & + \\
\hline F25 & Técnico & $\begin{array}{lr}\text { Excesso } & \text { de } \\
\text { manuseio } & \text { do } \\
\text { material devido à } \\
\text { separação } & \text { do } \\
\text { layout (Linha } & \text { e } \\
\text { célula) } & \end{array}$ & + & + & & & & & + \\
\hline F26 & Técnico & $\begin{array}{l}\text { Necessidade de um } \\
\text { estoque de peças } \\
\text { pintadas devido a } \\
\text { baixa confiabilidade } \\
\text { do processo. }\end{array}$ & + & & & & & & \\
\hline F27 & Técnico & $\begin{array}{l}\text { Dificuldade } \\
\text { rastrear as peças } \\
\text { no sistema. }\end{array}$ & & + & & & & & + \\
\hline F28 & Técnico & $\begin{array}{lr}\text { Falta de } & \text { um } \\
\text { software } & \text { para } \\
\text { auxiliar na } & \text { aestão }\end{array}$ & + & + & & & & & + \\
\hline
\end{tabular}

Com o Quadro 5, pode-se visualizar que os fatores organizacionais devem ser priorizados no momento da criação do plano de ação, visto que são os que mais influenciam as barreiras, tanto para aumentar a sua intensidade quanto para diminuir. Além disso, são fatores mais facilmente controlados pelo setor do que os fatores externos (MARODIN; SAURIN, 2015).

Ao aprofundar a análise do contexto organizacional, verifica-se que fato de o setor estudado ter sido recentemente anexado a outro setor da planta ocasiona dificuldades na compilação de um histórico de desempenho, assim como no menor conhecimento sobre o processo pelos novos gerentes e supervisores. Também nota-se que o compartilhamento do gerente e do supervisor com outro setor demonstrou potencializar uma grande quantidade de barreiras. Ao analisar esse fator de contexto aliado ao distanciamento físico da sala do gerente e dos supervisores, verifica-se uma dificuldade de se tomar decisões rápidas e precisas. 
Considerando-se os fatores técnicos do setor, percebe-se que quando eles influenciam uma barreira tendem a ser da forma a amplificá-las. Isso demonstra uma falta de investimento na parte técnica no setor estudado. Analisando-se do ponto de vista das barreiras, nota-se que as barreiras B27, B10, B23 e B1 são as mais influenciadas pelos fatores de contexto do setor, facilitando, assim, a criação de um plano para a sua melhoria.

\subsection{Influência dos fatores de contexto nas barreiras}

Ao analisar as influências entre barreiras da implantação da PE, buscou-se, inicialmente, classificá-las em 4 tipos (Figura 2), a partir da análise do Apêndice 1.

Através da Figura 2, compreende-se que uma das barreiras mais importantes para gerenciar a implantação da PE no setor é a barreira B27, visto que foi a única considerada uma barreira de união e, dessa forma, age como um elo entre as demais. Também se confirmou a suspeita, dos responsáveis pelo setor, da importância do controle dos indicadores (B27) para o sucesso da implantação da PE. O diagnóstico mostra ainda que seis barreiras foram rotuladas como independente, por apresentarem alto poder de influência sobre as demais e baixa dependência.

Figura 2 - Classificação do comportamento das barreiras em 4 tipos

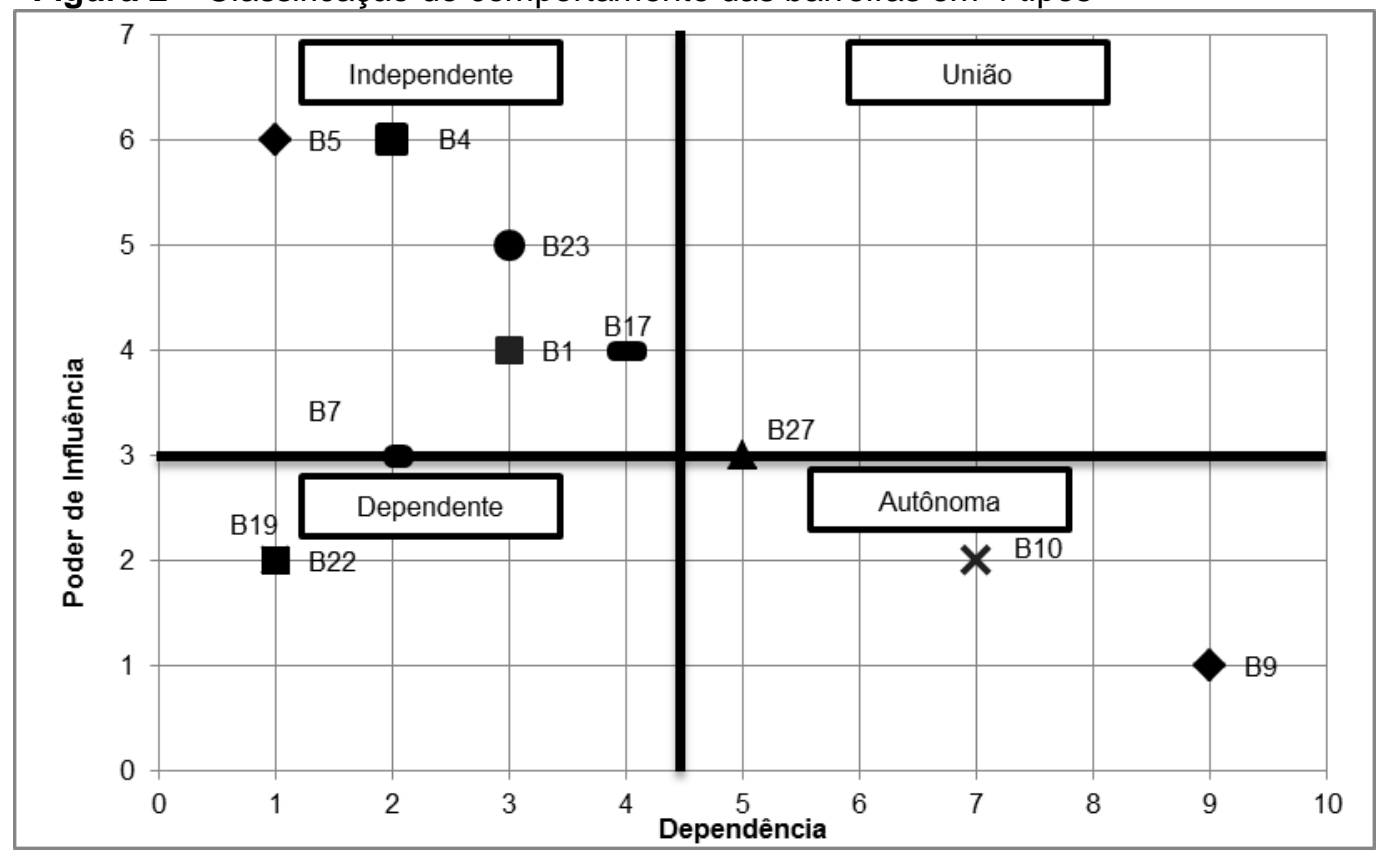

Revista Produção Online, Florianópolis, SC, v. 16, n. 1, p. 313-341, jan./mar. 2016. 
Seguindo a análise das barreiras, montou-se o Apêndice 2 com o intuito de gerar o mapa da Figura 3 que facilita a visualização das relações das barreiras. Através dele, pode-se verificar que ao diminuir B7, também reduz B10 e, por consequência, B9. Dessa forma, ao valorizar ações de impacto a médio e longo prazo (B7), facilita-se a gestão do processo de implantação de melhorias (B10), ao melhorar a gestão da implantação de melhorias (B10), otimiza-se a sustentação dessas melhorias a média e longo prazo (B9).

A Figura 3 também mostra que B4 (falta de recursos humanos) é influenciado pela B5 (falta de recursos financeiro). Isso decorre do fato de que o principal motivos para a falta de recursos humanos destinado a melhorias no setor é a falta de recursos financeiros destinada a esse ensejo.

Além disso, o mapa das relações (Figura 3) auxilia na visualização completa do efeito de cada barreira. Assim, pode-se verificar que a B22 (dificuldade em encontrar fornecedores que utilizam a PE), apesar de influenciar diretamente em apenas uma barreira (B1), interfere indiretamente em cinco barreiras (B23, B17, B27, B10 e B9). 
Figura 3 - Mapa do relacionamento entre barreiras

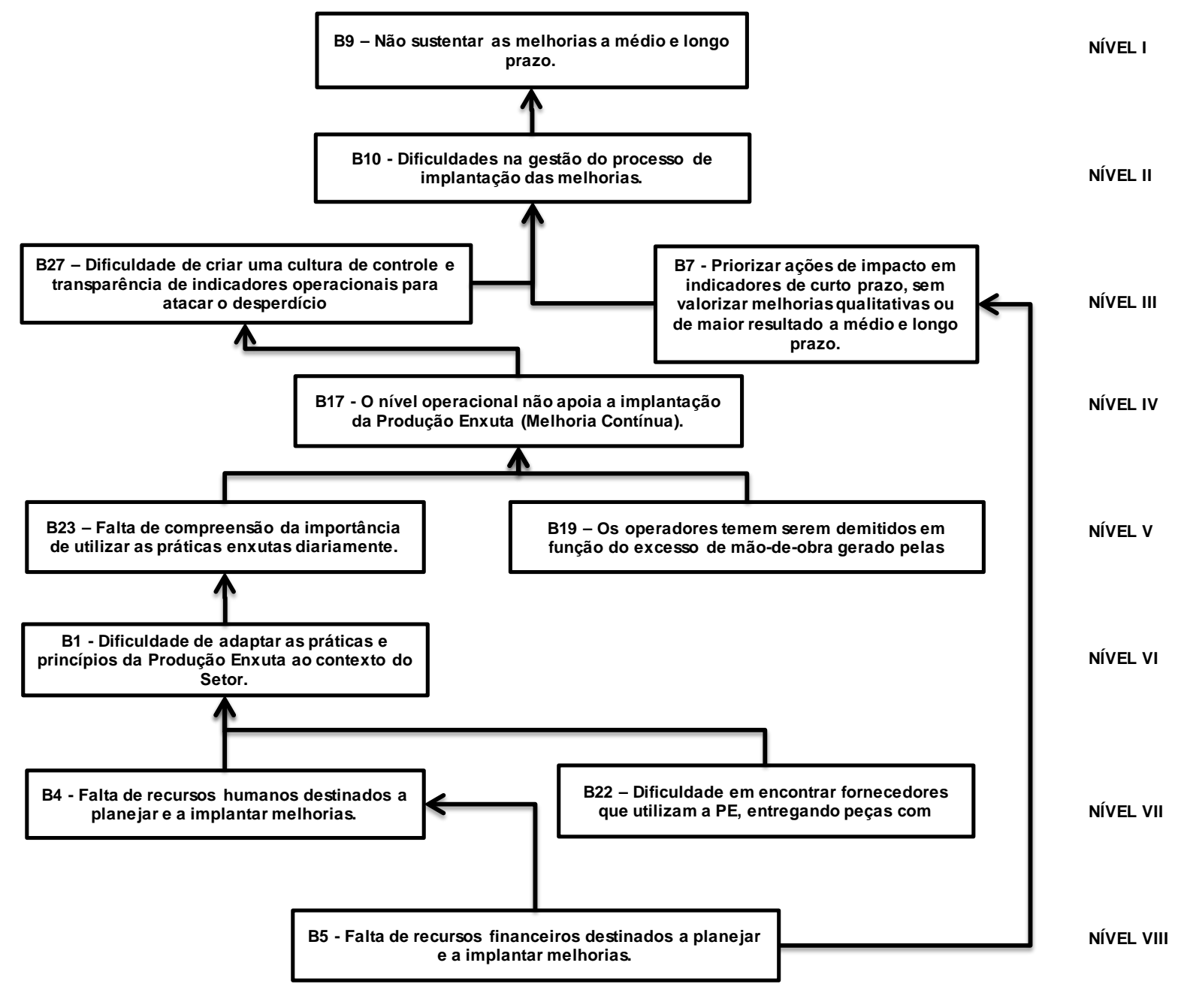

\subsection{Plano de ação para controlar as barreiras e sua análise}

A partir das análises das dificuldades do setor na implantação da PE e do contexto no qual a empresa está inserida, criou-se, em conjunto com o time de melhoria contínua do setor, um plano de ação contendo cinco partes e nove ações, conforme demonstrado no Quadro 6. 
Quadro 6 - Resumo do plano de ação

\begin{tabular}{|c|c|c|c|}
\hline Ação & $\begin{array}{l}\text { Barreiras atenuadas } \\
\text { pela ação }\end{array}$ & Responsável & Situação \\
\hline $\begin{array}{l}\text { A1 - Reunião de qualidade diária com } \\
\text { facilitadores e a equipe de melhoria } \\
\text { contínua do setor. }\end{array}$ & B1, B23, B17 & $\begin{array}{l}\text { Líder de produção } \\
\text { do setor }\end{array}$ & Implantada \\
\hline $\begin{array}{c}\text { A2 - Desdobramento dos indicadores de } \\
\text { qualidade e capacidade de resposta para } \\
\text { os times diariamente; }\end{array}$ & B27 & $\begin{array}{l}\text { Time de melhoria } \\
\text { contínua }\end{array}$ & Implantada \\
\hline $\begin{array}{c}\text { A3 - Otimizar a quantificação dos custos } \\
\text { de retrabalho e Scraps. }\end{array}$ & B5, B7 & $\begin{array}{l}\text { Responsável por } \\
\text { custos do setor }\end{array}$ & Em andamento \\
\hline $\begin{array}{c}\text { A4 - Desdobrar as metas de custos dos } \\
\text { times através do custo unitário de } \\
\text { produção para cada time }\end{array}$ & B5, B27 & $\begin{array}{l}\text { Responsável por } \\
\text { custos do setor }\end{array}$ & Implantada \\
\hline $\begin{array}{l}\text { A5 - Criar plano e indicadores para o time } \\
\text { de melhoria contínua do setor. }\end{array}$ & B1, B7, B10 & $\begin{array}{l}\text { Time de melhoria } \\
\text { contínua }\end{array}$ & Em estudo \\
\hline $\begin{array}{l}\text { A6 - Ter um representante do time de } \\
\text { melhoria contínua em todos os turnos. }\end{array}$ & B4, B10, B9 & $\begin{array}{l}\text { Time de melhoria } \\
\text { contínua }\end{array}$ & Implantada \\
\hline $\begin{array}{l}\text { A7 - Criação e atualização mensal de um } \\
\text { centro de informações para o setor }\end{array}$ & B10, B17, B19 & $\begin{array}{l}\text { Time de melhoria } \\
\text { contínua }\end{array}$ & Implantada \\
\hline $\begin{array}{l}\text { A8 - Realizar reuniões de nível gerencial } \\
\text { no setor. }\end{array}$ & B5 & Gerente do setor & Em andamento \\
\hline $\begin{array}{c}\text { A9 - Criação de etiquetas com código de } \\
\text { barras para cada peça. }\end{array}$ & B1 & $\begin{array}{l}\text { Time de melhoria } \\
\text { contínua }\end{array}$ & Em estudo \\
\hline
\end{tabular}

A primeira parte do plano trata-se de melhorar a transparência dos indicadores e incentivar a comunicação entre o time de melhoria contínua do setor e a operação, para que o auxilio aos times com problemas de qualidade e capacidade de resposta seja diário e ágil. Duas ações foram definidas para essa parte: a primeira (A1) é realizar uma reunião de qualidade diária entre os facilitadores de produção e a equipe de melhoria contínua, atenuando assim as barreiras B1, B23 e B17. A segunda ação (A2) foi elaborada para atenuar a barreira B27 e compreende o desdobramento dos indicadores de qualidade e capacidade de resposta para os times diariamente, colocando-se o seu resultado nos quadros de cada time produtivo, objetivando que o facilitador do time trabalhe na melhoria contínua do seu setor.

A segunda parte do plano contém duas ações e objetiva-se otimizar o controle financeiro do setor. A primeira ação (A3) é otimizar a quantificação dos custos de retrabalho e scraps, através de introdução de fichas de controle de volume de retrabalho diário e da mensuração dos custos dos produtos químicos (promotor, 
base e verniz) nos polímeros pintados e rejeitados, visto que, atualmente, considerase apenas os custos da aquisição do polímero. A segunda ação (A4) será desdobrar as metas de custos dos times, através do custo unitário de produção para cada time baseado no histórico dos últimos doze meses. Espera-se com a ação A3 atenuar as barreiras B5 e B7, já com a ação A4 diminuir as barreiras B5 e B27.

A terceira etapa do plano é composta por duas ações no qual busca-se melhorar a gestão interna do time de melhoria contínua, com o intuito de criar uma filosofia de longo prazo. Para isso, na primeira ação (A5) desenvolveu-se indicadores de qualidade e capacidade de resposta relacionados a problemas sob responsabilidade desse time, além de um quadro com as ações previstas para cada membro do time na semana (atenuar as barreiras B1, B7 e B10). A segunda ação (A6) é viabilizar a alocação de um representante do time de melhoria contínua no terceiro turno, buscando-se padronizar as ações de melhorias entre os turnos e, dessa forma, diminuir a barreiras B4, B10 e B9.

A quarta etapa do plano, composta por duas ações, visa aproximar os gerentes e supervisores da empresa com o setor estudado e, também. melhorar o ambiente interno do setor. A primeira ação (A7), que tem como intuito diminuir as barreiras B10, B17 e B19, abrange a criação e atualização mensal de um centro de informações para o setor, contendo quadro de reconhecimento para os membros, indicadores gerais e quadro com o processo de implantação de melhorias, oriundos de workshops no setor. A segunda etapa (A8) é realizar reuniões mensais de nível gerencial, com o intuito principal de reduzir a barreira B5, através da exposição do setor para funcionários com poder de decisão sobre investimentos financeiros dentro da planta. Essa ação (A8) é a única que não se pode conduzi-la em paralelo com as demais, visto que depende da criação do centro de informações (A7).

A quinta e última etapa do plano de ação tem como intuito facilitar e aperfeiçoar o controle de peças produzidas, que é realizado através de contagens manuais. Essa etapa contará com uma ação (A9) para a implantação de etiquetas com código de barras para cada peça pintada, que será lida no momento de entrada e saída do estoque e após a peça estar montada para ir para o cliente interno. Essa ação foi elaborada para reduzir a barreira B1, através da diminuição das dificuldades de controle de estoque e de rastreio de peças no setor. 
Posteriormente a preparação do plano de ação, elaborou-se uma avaliação dos efeitos das ações sobre os fatores de contexto e sobre as barreiras para a implantação da PE. Para tanto, realizou-se o preenchimento do Apêndice 3, cujo resultado é demonstrado no Quadro 7.

Quadro 7-Análise da influência das ações no contexto e nas barreiras
\begin{tabular}{|c|c|c|}
\hline Ação & $\begin{array}{c}\text { Fatores de contextos influenciados } \\
\text { positivamente pela ação }\end{array}$ & $\begin{array}{c}\text { Barreiras atenuadas devido a influência } \\
\text { da ação no seu contexto }\end{array}$ \\
\hline A1 & $\begin{array}{c}\text { F4, F9, F10, F11, F12, F15, F18, F22, } \\
\text { F5 }\end{array}$ & B1, B5, B27, B10, B4, B23, B9, B17, B7 \\
\hline A2 & F10, F18, F22, F26, F27, F6, F14 & B27, B10, B23, B9, B17, B5, B1, B19, B7 \\
\hline A3 & $F 26, F 27$ & B5, B27, B1 \\
\hline A5 & $F 9, F 10, F 15$ & B5, B27, B10, B4, B1, B23, B9, B17, B7 \\
\hline A6 & F10, F15, F22, F14 & B27, B10, B23, B9, B17, B7, B19 \\
\hline A7 & F7, F9, F10,F6 & B5, B10, B4, B27, B1, B23, B9, B17 \\
\hline A8 & F2, F3, F7, F9, F11, F12 & B4, B7, B5, B10, B27, B1, B9, B9, B17 \\
\hline A9 & F10, F25, F26, F27,F14 & B27, B10, B23, B9, B17, B5, B1, B19, B7 \\
\hline
\end{tabular}

Percebe-se, através do Quadro 7, que as barreiras que seriam atenuadas pelas ações (Quadro 6) coincidiram em sua maioria com as barreiras atenuadas pelo contexto (terceira coluna do Quadro 7), demonstrando que essas ações estão coerentes com seu objetivo. A exceção foi a ação $A 4$, que devido a sua característica específica, não possui potencial de alterar o contexto do setor nos fatores analisados, apesar de ter potencial de atenuar as barreiras B5 e B27 pela análise do time de melhoria do setor.

Através do Quadro 7, verifica-se também que dezoito diferentes fatores de contexto foram abrangidos pelas ações, portanto a maioria dos fatores de contexto identificados no setor foram compreendidos pelo plano de ação. Essa análise é importante para constatar a capacidade do plano de ação de modificar o contexto do setor e, consequentemente, diminuir as intensidades das barreiras para o processo de implantação da PE. 


\subsection{Comparação com o estudo aplicado}

Através da comparação com o estudo anterior realizado por Marodin e Saurin (2015), no qual aplicou-se pela primeira vez o método base desse presente estudo, organizou-se o Quadro 8 e o Quadro 9. Os dados da empresa A são relativos ao caso estudados nesse artigo, já os dados empresa B referem-se ao estudo aplicado por Marodin e Saurin (2015).

Quadro 8 - Comparação das empresas estudadas
\begin{tabular}{|c|c|c|}
\hline Empresas & A & B \\
\hline Local da planta & $\begin{array}{c}\text { Brasil (numa região com poucos } \\
\text { fornecedores enxutos) }\end{array}$ & $\begin{array}{c}\text { Estados Unidos da América (numa } \\
\text { região próxima de grandes fornecedores } \\
\text { enxutos) }\end{array}$ \\
\hline Tamanho da Planta & Grande & Grande \\
\hline Setor da Planta & Automobilístico & 1983 \\
\hline Ano de inauguração da planta & 2000 & 2001 \\
\hline Inicio da implantação da PE & 2000 & 200 stico \\
\hline
\end{tabular}

Através da análise das empresas (Quadro 8), verifica-se que ambas possuem o mesmo porte e estão situadas no mesmo ramo de atuação. A planta da empresa $A$ possui a vantagem de ser mais nova e ser projetada com o intuito de ser uma planta enxuta em comparação com a planta da empresa B que iniciou a implantação da PE 18 anos após a sua inauguração. Por outro lado, a empresa B está localizada numa região próxima a diversos fornecedores do ramo automobilístico, já a empresa $A$ está distante de grande parte dos seus fornecedores.

Quadro 9-Comparação dos resultados do estudo
\begin{tabular}{|c|c|c|}
\hline Empresa & A & B \\
\hline Entrevistados & 13 & 14 \\
\hline Barreiras avaliadas & 27 & 2,3 \\
\hline Intensidade média das barreiras & 2,8 & 14 \\
\hline Barreiras priorizadas & 11 & 34 \\
\hline Fatores de contexto analisados & 28 & 3 \\
\hline Ações elaboradas & 9 & 2 \\
\hline
\end{tabular}


Com relação aos resultados do Quadro 9, é importante ressaltar que o estudo aplicado na empresa A foi localizado num setor problemático da planta, já o estudo aplicado na empresa $B$ foi relativo a toda planta. Em função disso, percebe-se que na empresa A foram elencados um número maior de barreiras (27 barreiras) e, mesmo assim, a sua média de intensidade percebida pelos entrevistados foi maior que o da empresa B.

Outra importante diferença nos estudos é com relação ao número de ações. Como o estudo na empresa $A$ foi realizado em um setor específico da planta, foram elaboradas nove ações mais específicas, já para a empresa B foram elaboradas três ações amplas. Além disso, o presente estudo acrescentou a análise da influência das ações no contexto e nas barreiras (Apêndice 3 e Quadro 7), com o intuito de possibilitar uma crítica qualificada do plano de ação, facilitando a priorização das ações criadas e a visualização de oportunidades de melhorias nas barreiras não atenuadas.

Apesar dessas diferenças, os dois estudos foram capazes de fazer com que os gestores visualizassem as suas dificuldades e criassem ações condizentes aos fatores de contexto e as barreiras da implantação da PE das suas empresas.

\section{CONCLUSÃO}

A principal contribuição do estudo foi aperfeiçoar o método de gerenciamento de barreiras desenvolvido por Marodin e Saurin (2015). De forma consistente, o presente estudo avança em relação à proposta original por: (i) testar a ferramenta em um novo ambiente; (ii) desenvolver mecanismos para monitorar as mudanças no contexto; e (iii) construir meios para o gerenciamento das barreiras.

Para isso, duas novas etapas foram adicionadas ao método: a análise do plano de ação e a priorização das barreiras a serem abordadas. A análise do plano de ação mostra como as barreiras e os fatores de contexto modificam-se de acordo com as intervenções realizadas no sistema. Nota-se, através desta análise, que as ações projetadas para atenuar barreiras também repercutem sobre os fatores de contexto, alterando a intensidade dos mesmos. Como consequência, a modificação dos fatores de contexto também influenciam outras barreiras, demonstrando-se assim que os efeitos produzidos pela ação vão além daquelas barreiras 
imediatamente atenuadas pelo plano de ação. Essa contribuição é relevante, pois ressalta a característica sistêmica da abordagem proposta, onde as inter-relações entre barreiras, fatores de contexto e ações são tratadas de maneira explícita.

A etapa de priorização, por sua vez, mostrou-se necessária devido ao elevado número de barreiras encontradas durante a nova aplicação do método. Ao total, vinte e sete foram identificadas, contra quatorze na aplicação original. A escassez de recursos para atuar em todas as barreiras pode ser considerada como o principal motivador para conceber essa nova etapa no método.

Outro aporte do estudo foi a identificação de fatores de contexto do setor estudado, vinte e oito ao total. A sistemática para identificação e classificação destes fatores pode servir de base para novos estudos em empresas com contexto semelhante. Além disso, houve um incremento da lista de barreiras já identificadas, através da descoberta de seis novas barreiras presentes na literatura e de sete novas barreiras identificadas no setor estudado. É importante ressaltar que esses acréscimos emanaram em conjunto com análises das influências destes na implantação da PE.

De maneira sumária, a verificação do método através da sua aplicação e comparação com o estudo de Marodin e Saurin (2015) fornece uma maior base de conteúdo teórico e prático sobre as barreiras relacionadas à PE. Por um lado, 0 refinamento do método representa uma contribuição teórica do estudo, uma tentativa de tornar a ferramenta mais robusta e replicável. Por outro, a contribuição prática do estudo está em proporcionar o entendimento pela empresa do seu contexto e das suas barreiras, resultando na criação e análise de um plano de ação.

A principal limitação do estudo, novamente, decorre de o método ter sido aplicado em uma empresa com larga experiência em PE. Em estudos futuros, 0 método ainda precisa ser testado em empresas que estejam em diferentes momentos da implantação enxuta, para verificar a influência dos fatores de contexto e barreiras presentes nestas situações. Outro direcionamento futuro é aplicar o método em empresas de porte e setores diferentes, visto que os estudos realizados até então foram conduzidos em empresas de grande porte e do setor automobilístico. Por último, também se recomenda a criação de um mapa que 
conecte os fatores de contexto com as barreiras priorizadas, facilitando, assim a elaboração do plano de ação.

\section{REFERÊNCIAS}

ACHANGA, P.; SHEHAB, E.; ROY, R; NELDER, G. Critical success factors for lean implementation within SMEs. Journal of Manufacturing Technology Management, v.17, n. 4, p. 460-471, 2006. http://dx.doi.org/10.1108/17410380610662889

AIJ, K. H.; SSIMONS, F. E.; WIDDERSHOVEN, G. A. M.; VISSE, M. Experiences of leaders in the implementation of Lean in a teaching hospital - barriers and facilitators in clinical practices: a qualitative study. BMJ Open, v. 2013, n. 3, p. 1-8, 2013. http://dx.doi.org/10.1136/bmjopen$\underline{2013-003605}$

BHASIN, S. An appropriate change strategy for lean success. Management Decision, v. 50, n. 3, p. 439 - 458, 2012. http://dx.doi.org/10.1108/00251741211216223

BHASIN, S.; BURCHER, P. Lean viewed as a philosophy. Journal of Manufacturing Technology Management, v. 17, n.1, p. 56-72, 2006.

http://dx.doi.org/10.1108/17410380610639506

BELEKOUKIAS, I.; GARZA-REYES, J. A.; KUMAR, V. The impact of lean methods and tools on the operational performance of manufacturing organisations. International Journal of Production Research, v. 52, n. 18, p. 5346-5366, 2014. http://dx.doi.org/10.1080/00207543.2014.903348

BORTOLOTTI, T.; BOSCARI, S.; DANESE, P. Successful lean implementation: organizational culture and soft lean practices. International Journal of Production Economics, v. 160, p. 182-201, 2015. http://dx.doi.org/10.1016/j.ijpe.2014.10.013

BOYLE, T. A.; SCHERRER-RATHJE, M.; STUART, I. Learning to be lean: the influence of external information sources in lean improvements. Journal of Manufacturing Technology Management, v. 22, n. 5, p. 587-603, 2011. http://dx.doi.org/10.1108/17410381111134455

CASTILLO, G.; ALARCON, L. F.; GONZALEZ, V. A. Implementing lean production in copper mining development projects: case study. Journal of Construction Engineering and Management, v. 141, n. 1, 1-11, 2015. http://dx.doi.org/10.1061/(ASCE)CO.1943$\underline{7862.0000917}$

DENNIS, P. Produção lean simplificada. Porto Alegre: Bookman, 2008.

EMILIANI, M. L.; STEC, D. J. Leaders lost in transformation. Leadership \& Organization Development Journal, v. 26, n. 5, p. 370-387, 2005.

http://dx.doi.org/10.1108/01437730510607862

HOFER, C.; EROGLU, C.; HOFER, A. R. The effect of lean production on financial performance: the mediating role of inventory leanness. International Journal of Production Economics, v. 138, n. 2, p. 242-253, 2012. http://dx.doi.org/10.1016/j.ijpe.2012.03.025 
JADHAV, J. R.; MANTHA, S. S.; RANE, S. B. Exploring barriers to lean implementation. International Journal of Lean Six Sigma, v. 5, n. 2, p. 122-148, 2014. http://dx.doi.org/10.1108/IJLSS-12-2012-0014

LEAN ENTERPRISE INSTITUTE. (2007). Middle managers are biggest obstacle to lean enterprise. Disponível em:<http://www.lean.org/WhoWeAre/NewsArticleDo cuments/Web_Lean_survey.pdf>. Acesso em: 25 ago. 2015.

MARODIN, G. A.; SAURIN, T. A. Managing barriers to lean production implementation: context matters. International Journal of Production Research, v. 53, n. 13, p. 3947-3962, 2015. http://dx.doi.org/10.1080/00207543.2014.980454

MARODIN, G. A.; SAURIN, T. A. Implementing lean production systems: research areas and opportunities for future studies. International Journal of Production Research, v. 51, n. 22, p. 6663-6680, 2013. http://dx.doi.org/10.1080/00207543.2013.826831

MARODIN, G. A.; SAURIN, T. A.; FETTERMANN, D. C. Uma sistemática para a avaliação de riscos na implantação da produção enxuta. Revista Produção Online, v14, n1, p. 364-401, 2014. http://dx.doi.org/10.14488/1676-1901.v14.i1.1667

MOYANO-FUENTES, J.; SACRISTIÁN-DÍAZ, M. Learning on lean: a review of thinking and research. International Journal of Operations \& Production Management, v. 32, n. 5, p. 551-582, 2012. http://dx.doi.org/10.1108/01443571211226498

SAGE, A. P. Interpretive structural modeling: methodology for large-scale systems. New York: McGraw-Hill, 1977.

SAURIN, T. A; RIBEIRO, J. L. D.; MARODIN, G. A. Identificação de oportunidades de pesquisa a partir de um levantamento da implantação da produção enxuta em empresas do Brasil e do exterior. Gestão e Produção, v. 17, n. 4, p. 829-841, 2010. http://dx.doi.org/10.1590/S0104$\underline{530 \times 2010000400015}$

SCHERER, J. O.; RIBEIRO, J. L. D. Proposição de um modelo para análise dos fatores de risco em projetos de implantação da metodologia lean. Gestão e Produção, v. 20, n. 3, p.537553, 2013. http://dx.doi.org/10.1590/S0104-530X2013000300004

SIM, K. L.; ROGERS, J. W. Implementing lean production systems: barriers to change.

Management Research News, v. 32, n. 1, p. 37-49, 2008.

http://dx.doi.org/10.1108/01409170910922014

SHANG, G.; PHENG, L. S. Barriers to lean implementation in the construction industry in China. Journal of Technology Management in China, v. 9, n. 2, p. 155-173, 2014.

http://dx.doi.org/10.1108/JTMC-12-2013-0043

SOUZA, L. B; PIDD, M. Exploring the barriers to lean health care implementation. Public Money \& Management, v. 31, n. 1, p. 59-66, 2011.

http://dx.doi.org/10.1080/09540962.2011.545548

SUSILAWATI, A.; TAN, J.; BELL, D.; SARWAR, M. Fuzzy logic based method to measure degree of lean activity in manufacturing industry. Journal of Manufacturing Systems, v. 34, p. 1-11, 2015. http://dx.doi.org/10.1016/j.jmsy.2014.09.007 
TAYLOR, A.; TAYLOR, M.; MCSWEENEY, A. Towards greater understanding of success and survival of lean systems. International Journal of Production Research, v. 51, n. 22, p. 66076630, 2013. http://dx.doi.org/10.1080/00207543.2013.825382

VINODH, S.; SHIVRAMAN, K. R.; VISWESH, S. AHP-based lean concept selection in a manufacturing organization. Journal of Manufacturing Technology Management, v. 23, n. 1, p. 124-136, 2011. http://dx.doi.org/10.1108/17410381211196320

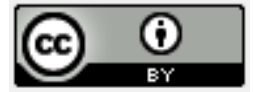

Artigo recebido em 05/09/2015 e aceito para publicação em 03/11/2015

DOI: $\underline{\text { http://dx.doi.org/ 10.14488/1676-1901.v16i1.2157 }}$ 
Apêndice 1. Matriz de relações entre as barreiras

\begin{tabular}{|c|c|c|c|c|c|c|c|c|c|c|c|}
\hline $\begin{array}{c}\text { A barreira da linha influencia a barreira da } \\
\text { coluna }\end{array}$ & B5 & B22 & B27 & B10 & B19 & B23 & B4 & B7 & B9 & B17 & B1 \\
\hline $\begin{array}{l}\text { B5 - Falta de recursos financeiros destinados a } \\
\text { planejar e a implantar melhorias. }\end{array}$ & 1 & 0 & 1 & 1 & 0 & 0 & 1 & 1 & 1 & 0 & 0 \\
\hline $\begin{array}{l}\text { B22 - Dificuldade em encontrar fornecedores que } \\
\text { utilizam a PE, entregando peças com qualidade e } \\
\text { pontualidade. }\end{array}$ & 0 & 1 & 0 & 0 & 0 & 0 & 0 & 0 & 0 & 0 & 1 \\
\hline $\begin{array}{l}\text { B27 - Dificuldade de criar uma cultura de controle } \\
\text { e transparência de indicadores operacionais para } \\
\text { atacar o desperdício }\end{array}$ & 0 & 0 & 1 & 1 & 0 & 0 & 0 & 0 & 1 & 0 & 0 \\
\hline $\begin{array}{l}\text { B10 - Dificuldades na gestão do processo de } \\
\text { implantação das melhorias. }\end{array}$ & 0 & 0 & 0 & 1 & 0 & 0 & 0 & 0 & 1 & 0 & 0 \\
\hline $\begin{array}{l}\text { B19 - Os operadores temem serem demitidos em } \\
\text { função do excesso de mão-de-obra gerado pelas } \\
\text { melhorias implantadas }\end{array}$ & 0 & 0 & 0 & 0 & 1 & 0 & 0 & 0 & 0 & 1 & 0 \\
\hline $\begin{array}{l}\text { B23 - Falta de compreensão da importância de } \\
\text { utilizar as práticas enxutas diariamente. }\end{array}$ & 0 & 0 & 1 & 1 & 0 & 1 & 0 & 0 & 1 & 1 & 0 \\
\hline $\begin{array}{l}\text { B4 - Falta de recursos humanos destinados a } \\
\text { planejar e a implantar melhorias. }\end{array}$ & 0 & 0 & 1 & 1 & 0 & 1 & 1 & 0 & 1 & 0 & 1 \\
\hline $\begin{array}{l}\text { B7 - Priorizar ações de impacto em indicadores de } \\
\text { curto prazo, sem valorizar melhorias qualitativas ou } \\
\text { de maior resultado a médio e longo prazo. }\end{array}$ & 0 & 0 & 0 & 1 & 0 & 0 & 0 & 1 & 1 & 0 & 0 \\
\hline $\begin{array}{l}\text { B9 - Não sustentar as melhorias a médio e longo } \\
\text { prazo. }\end{array}$ & 0 & 0 & 0 & 0 & 0 & 0 & 0 & 0 & 1 & 0 & 0 \\
\hline $\begin{array}{l}\text { B17 - O nível operacional não apoia a implantação } \\
\text { da Produção Enxuta (Melhoria Contínua). }\end{array}$ & 0 & 0 & 1 & 1 & 0 & 0 & 0 & 0 & 1 & 1 & 0 \\
\hline $\begin{array}{l}\text { B1 - Dificuldade de adaptar as práticas e princípios } \\
\text { da Produção Enxuta ao contexto do setor de } \\
\text { Pintura de Para-choques. }\end{array}$ & 0 & 0 & 0 & 0 & 0 & 1 & 0 & 0 & 1 & 1 & 1 \\
\hline
\end{tabular}

\section{Apêndice 2. Classificação das barreiras em níveis}

\begin{tabular}{|c|c|c|c|}
\hline Bn & Barreiras que influenciam Bn & Barreiras que são influenciadas por Bn & Nível \\
\hline B5 & - & B27, B10, B4, B7, B9 & Nível I \\
\hline B22 & - & Bível II \\
\hline B27 & B5, B23, B4, B17 & B10, B9 & Nível VI \\
\hline B10 & B5, B27, B23, B4, B7, B17 & B9 & Nível VII \\
\hline B19 & B10, B7 & B17 & Nível IV \\
\hline B23 & B4, B1 & B27, B10, B9, B17 & Nível IV II \\
\hline B4 & B5 & B27, B10, B23, B9, B1 & Nível VI \\
\hline B7 & B5 & B10, B9 & Nível VIII \\
\hline B9 & B5, B27, B10, B23, B4, B7, B17, B1 & B27, B10, B9 & Nível V \\
\hline B17 & B19, B23, B1 & B23, B7, B9, B17 & Nível III \\
\hline B1 & B22, B4 & - & \\
\hline
\end{tabular}




\section{Apêndice 3. Influência das ações nos fatores de contexto}

\begin{tabular}{|c|c|c|c|c|c|c|c|c|c|c|c|c|c|c|c|c|c|c|c|c|c|c|c|c|c|c|c|c|}
\hline $\begin{array}{l}\text { Ações / } \\
\text { Fatores } \\
\text { de } \\
\text { contexto }\end{array}$ & F1 & F2 & F3 & F4 & F5 & F6 & F7 & F8 & F9 & F10 & F11 & F12 & F13 & F14 & F15 & F16 & F17 & F18 & F19 & F20 & F21 & F22 & F23 & F24 & F25 & F26 & F27 & F28 \\
\hline A11 & & & & - & + & & & & - & - & - & - & & & - & & & - & & & & - & & & & & & \\
\hline A12 & & & & & & + & & & & - & & & & + & & & & - & & & & - & & & & - & - & \\
\hline A21 & & & & & & & & & & & & & & & & & & & & & & & & & & - & - & \\
\hline A22 & & & & & & & & & & & & & & & & & & & & & & & & & & & & \\
\hline A31 & & & & & & & & & - & - & & & & & - & & & & & & & & & & & & & \\
\hline A32 & & & & & & & & & & - & & & & + & - & & & & & & & - & & & & & & \\
\hline A41 & & & & & & + & - & & - & - & & & & & & & & & & & & & & & & & & \\
\hline A42 & & - & - & & & & - & & - & & - & - & & & & & & & & & & & & & & & & \\
\hline A51 & & & & & & & & & & - & & & & + & & & & & & & & & & & - & - & - & \\
\hline
\end{tabular}

Revista Produção Online, Florianópolis, SC, v. 16, n. 1, p. 313-341, jan./mar. 2016. 